\title{
Material Flow Analysis of Plastic Waste in Qatar: focusing on the Marine Environment
}

\author{
Danah Alagha, John N. Hahladakis \\ Qatar University \\ da1704627@qu.edu.qa, ichachladakis@qu.edu.qa
}

\section{ABSTRACT}

As the population continues, the generation of waste and specifically plastic waste, has also increased significantly in the past decades both globally and regionally, However, little attention has been directed to this problem in the region.

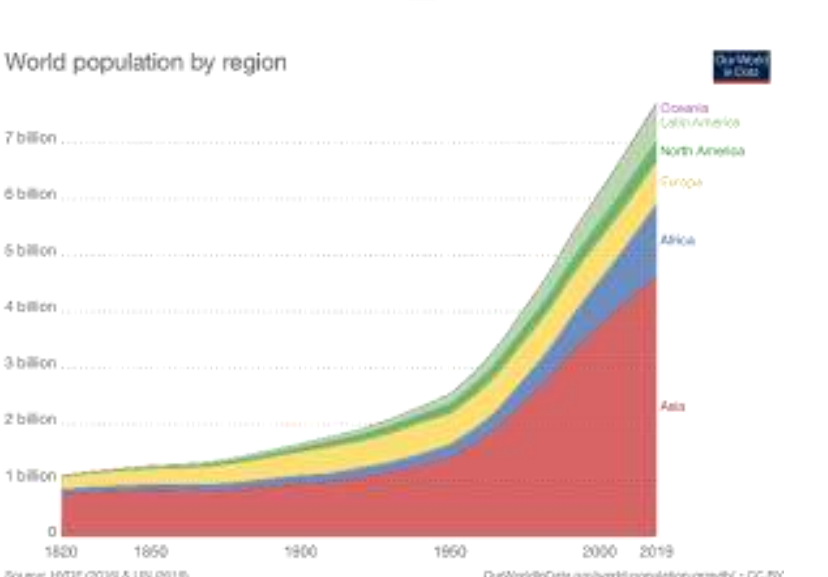

This study aims to delineate and map the status of the plastic waste problem Qatar with a focus on the plastic inflow to the marine environment. A generic material flow diagram was built using a material flow analysis software named STAN, to depict the flow of the plastic waste. The study focuses on the plastic waste in the marine environment, depicting the different types, sizes and shapes of plastic particles. As well as the recovery and recycling efforts that have been made, in efforts to reduce plastic waste and minimize the risk of plastic on the environment.

\section{OBJECTIVES}

Delineate and map the status of the plastic waste problem in the Arabian Gulf region. - Build a generic material flow diagram using STAN software to depict plastic flow.

- Explore the different recycling efforts in the region.

\section{METHODOLOGY}

\section{$>$ Literature Review}

The information presented for this poster was obtained through extensive literature review on marine litter and plastics in Qatar. The following keywords were used: Marine litter, Plastics, Arabian Gulf, Qatar; in various databases such as 'ScienceDirect ${ }^{\circledR}$ ', 'Google Scholar ${ }^{\circledR}$ ', 'Scopus ${ }^{\circledR}$ and 'Researchgate $\AA$. To gain more insights into the local efforts, several calls and meeting were conducted to various recycling facilities in Qatar as well as research centers (QEERI). Other local resources were taken into account, such as the State of Qatar's Ministry of Commerce and Industry website.

\section{STAN Software}

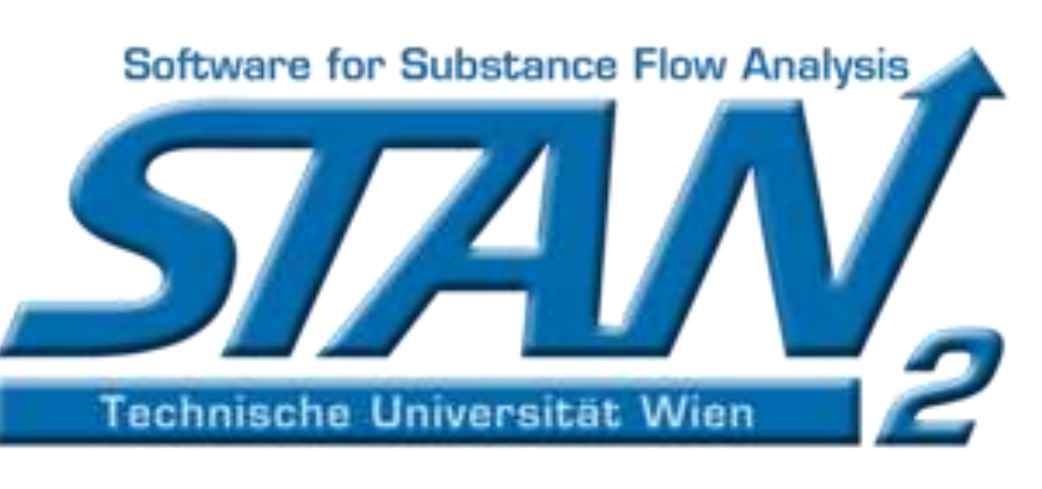

Using the STAN (2.6.801) software (subSTance flow ANalysis), we were able to conctruct a material flow diagram to depict the flow of plastic waste in Qatar, from generation, to collection, to recovery, recycling and exports. Several subsystems were created within, to provide an expanded view of the flows.

\section{DISCUSSION}

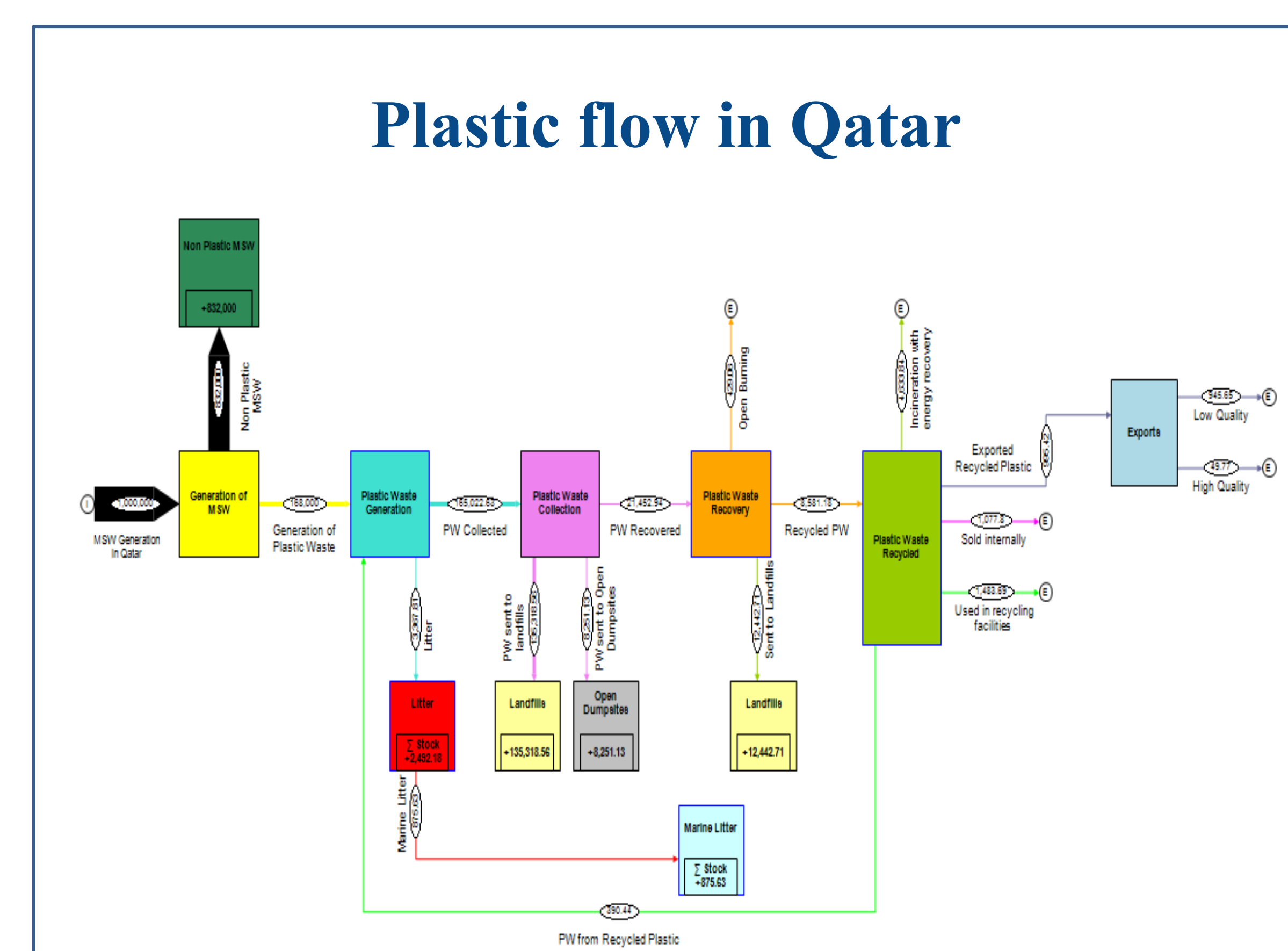

Figure 1. MFA of plastic in Qatar for the year 2016.

The general processes covered in the above MFD include generation of municipal solid waste and plastic waste, collection of plastic waste, littering, landfilling, open dumpsites, plastic waste recovery, recycling and exports.

\section{Generation of Waste}

The MFD starts with the generation of municipal solid waste in Qatar. The generation of MSW in Qatar is estimated to be a million tonnes per year (Al-Salem et al., 2020) and the plastic waste generated to be 168000 tonnes per year (Ghayebzadeh et al., 2020). This high generation of MSW and plastic waste can be attributed to the increasing rates of population growth, that happened as a result of the sudden economic boom following the discovery of oil. With higher population rates, comes higher demands and increasing waste generation rates.
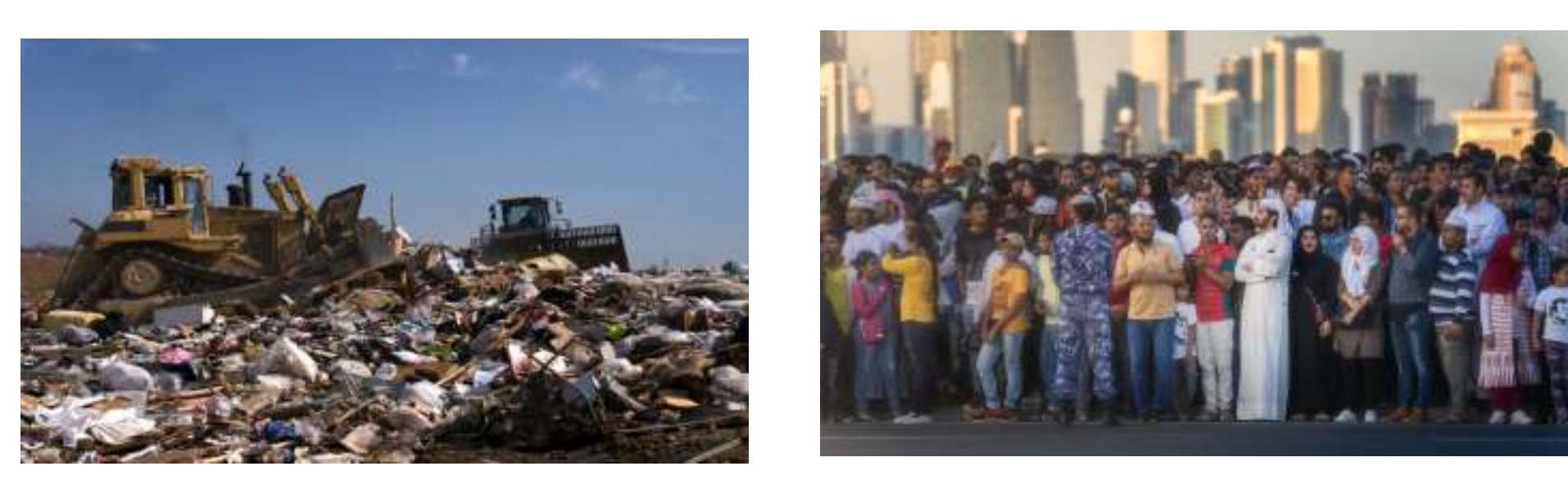

Plastic Collection and Litter

Based on the STAN software calculation, $98 \%$ of the waste is collected and the rest is littered $(2 \%)$. The litter process is split into two flows, land litter accounting for $74 \%$ of the littered waste, and $26 \%$ which comprises the marine litter.

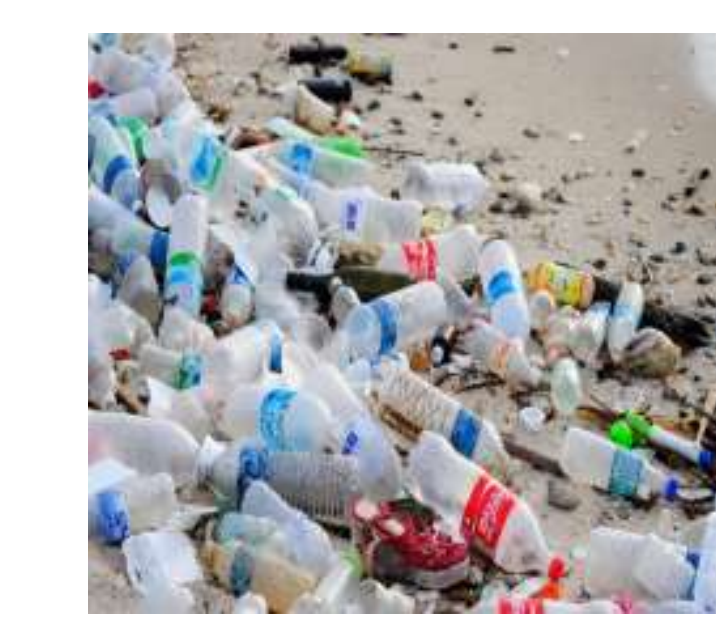

$>\quad$ Landfills and Open Dumpsites

Landfilling is the most prevalent method of waste management in the country, with around $82 \%$ of the collected plastic waste being sent to controlled landfills around Qatar.

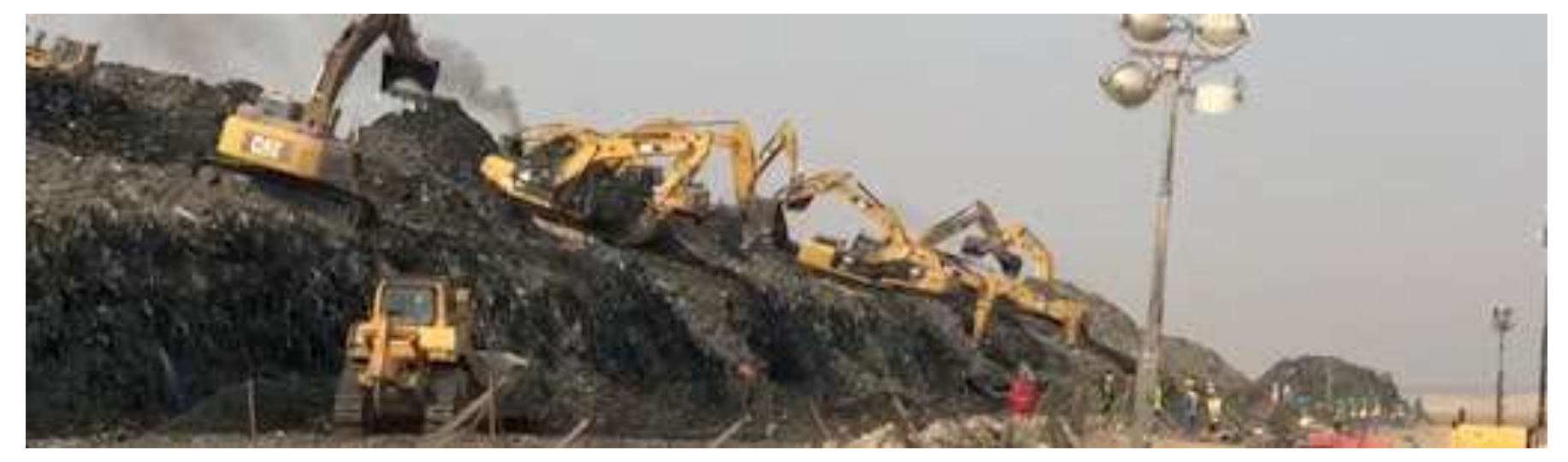

Open dumpsites are not commonly found in Qatar, as most of the plastic waste is monitored and regulated by the Ministry of Municipality and Environment. However, a small percentage of $5 \%$ was assigned to account for the illegal dumping that occurs on a irregular basis

\section{DISCUSSION}

\section{Recovery and Recycling}

$13 \%$ of the collected plastic waste in Qatar is recovered, as has been estimated by (Hahladakis and Aljabri, 2019). The most commonly recovered plastics being LDPE and LLDPE (55\%), followed by HDPE $(25 \%)$, PP (15\%) and others $(5 \%)$.

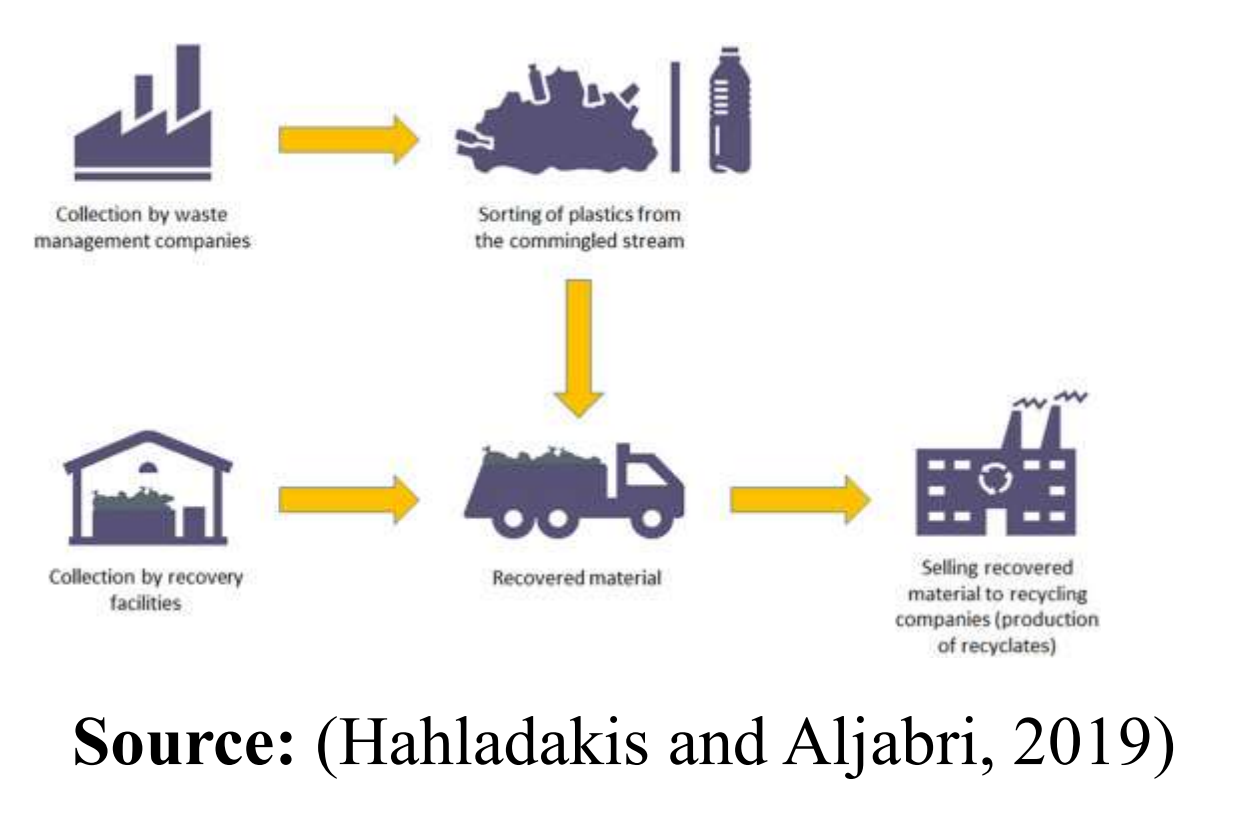

The recovered plastic waste is either, 1) recycled 2) burned openly 3 ) sent to landfills.

$40 \%$ of the recovered is recycled either by incineration with energy recover or undergone downcycling processes to produced new forms of plastics, such as mechanical recycling pathways, or chemical recycling pathways. Closed loop recycling methods are not as popular, but new initiatives are being put into place for the future.

Marine litter subsystem in Qatar

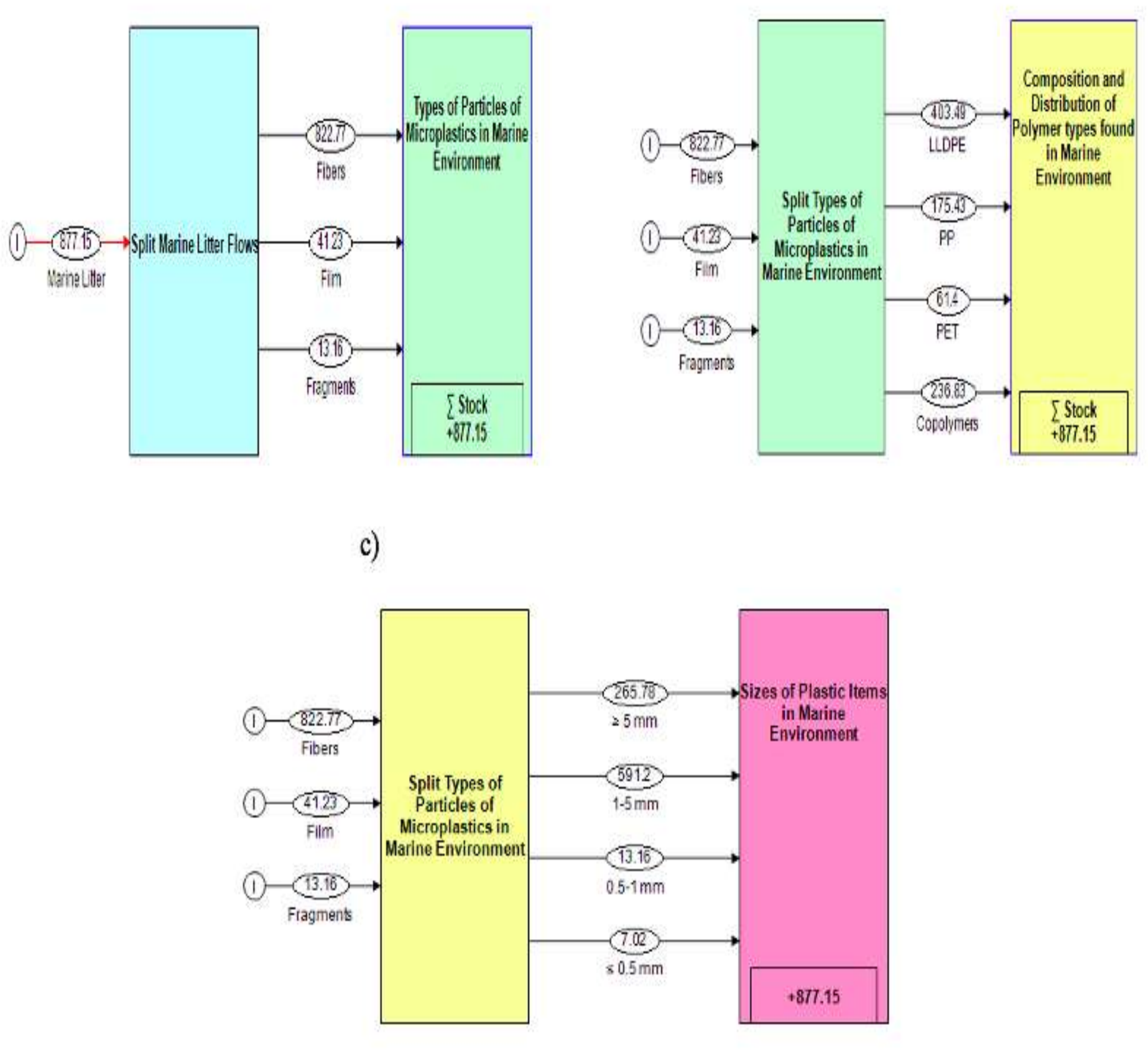

Figure 2. MFA of the marine litter subsystem in Qatar: (5a) Types of microplastic particles, (5b) Polymer Types, (5c) Plastic item sizes.

\section{Types of Particles of Microplastics}

Microplastic fibers are mainly made up of nylon and PET, both of which are commonly found in clothing. When municipal waters are disposed of in the marine environment, they are filled with fibers from washing clothes, making it the most pervasive marine contaminant with $93.8 \%$ of the total micoplastic types. Films are the next most commonly found $(4.7 \%)$, followed by fragments $(1.5 \%)$.

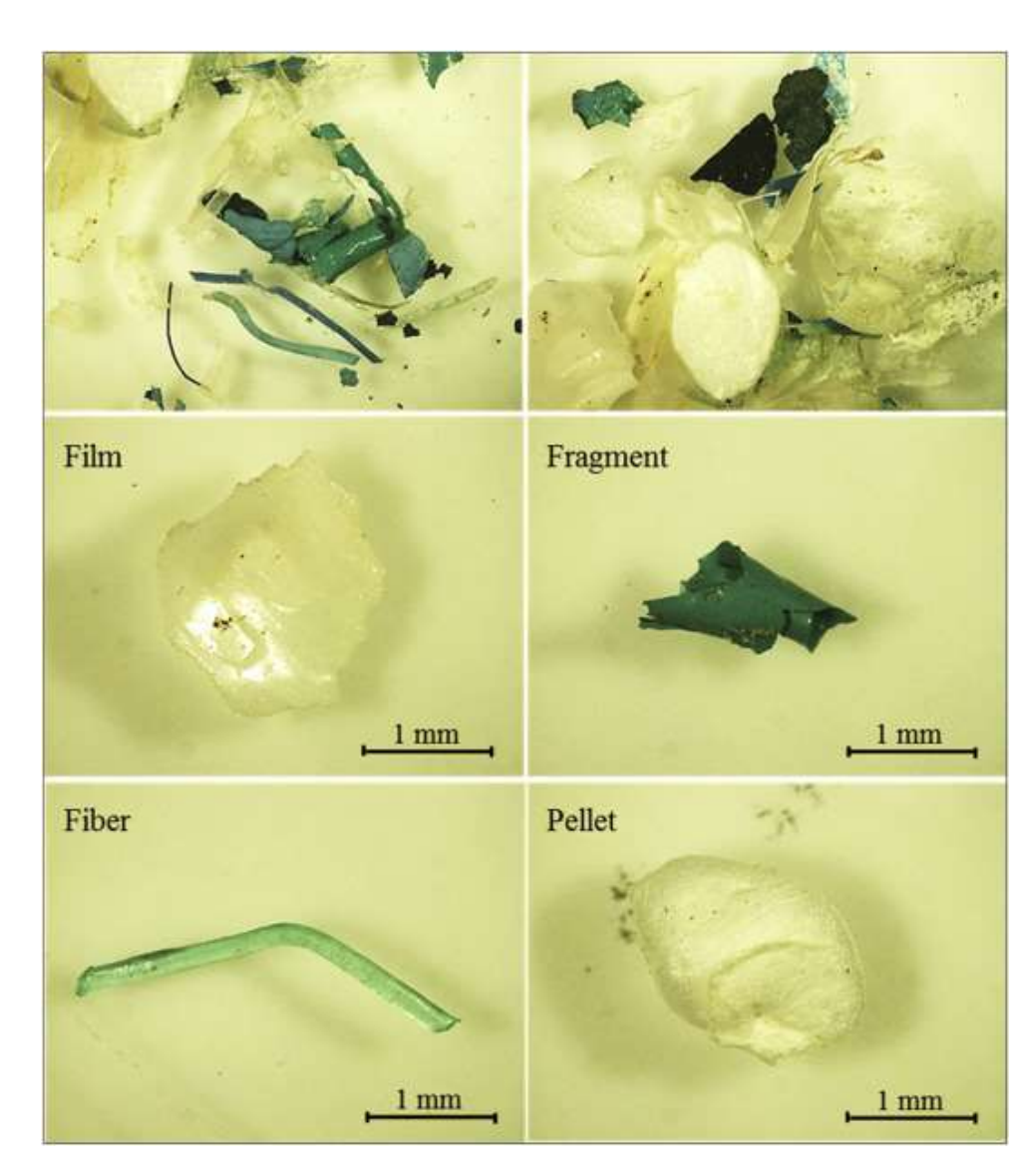

Source: (Kor and Mehdinia, 2020)

\section{DISCUSSION}

\section{$>\quad$ Polymer Types found in Marine \\ Environment}

LLDPE is the highest type of polymer found in Qatari waters (46\%),. LLDPE has penetrated almost all traditional markets for polyethylene; as it is used for plastic bags and sheets. Both of which are produced in great amounts in Qatar.

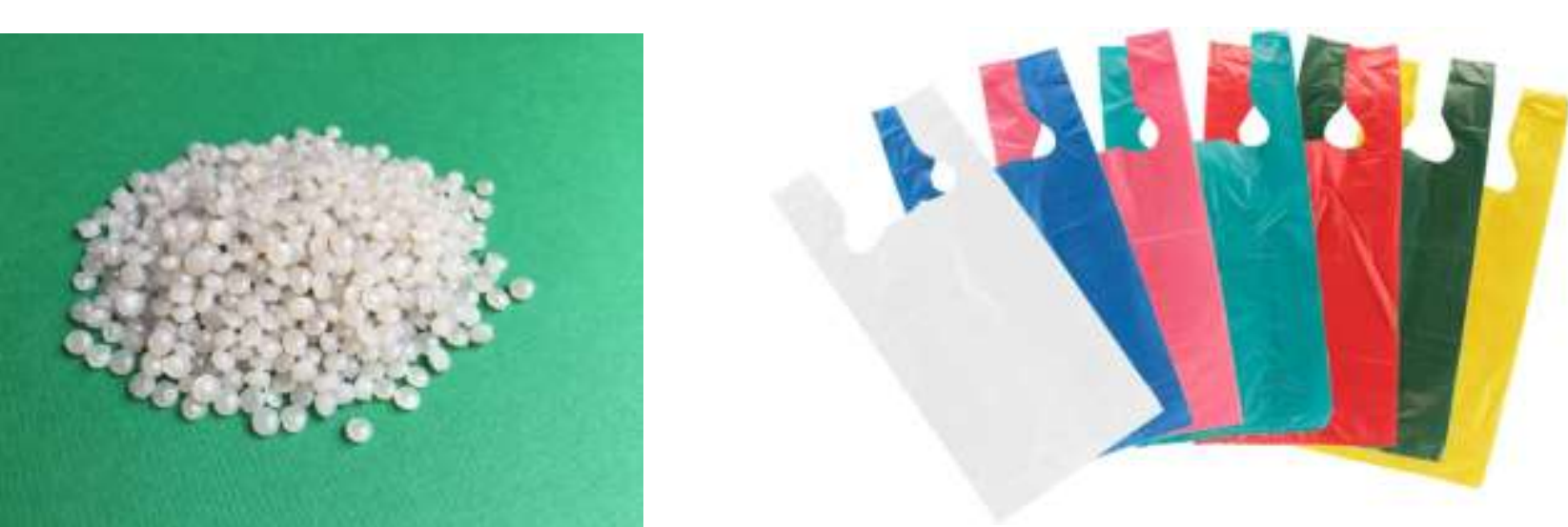

Polypropylene accounts for $20 \%$ of the plastics in the marine environment, a polymer which is commonly used in packaging materials, and makes up a large proportion of the plastic waste in Qatar.
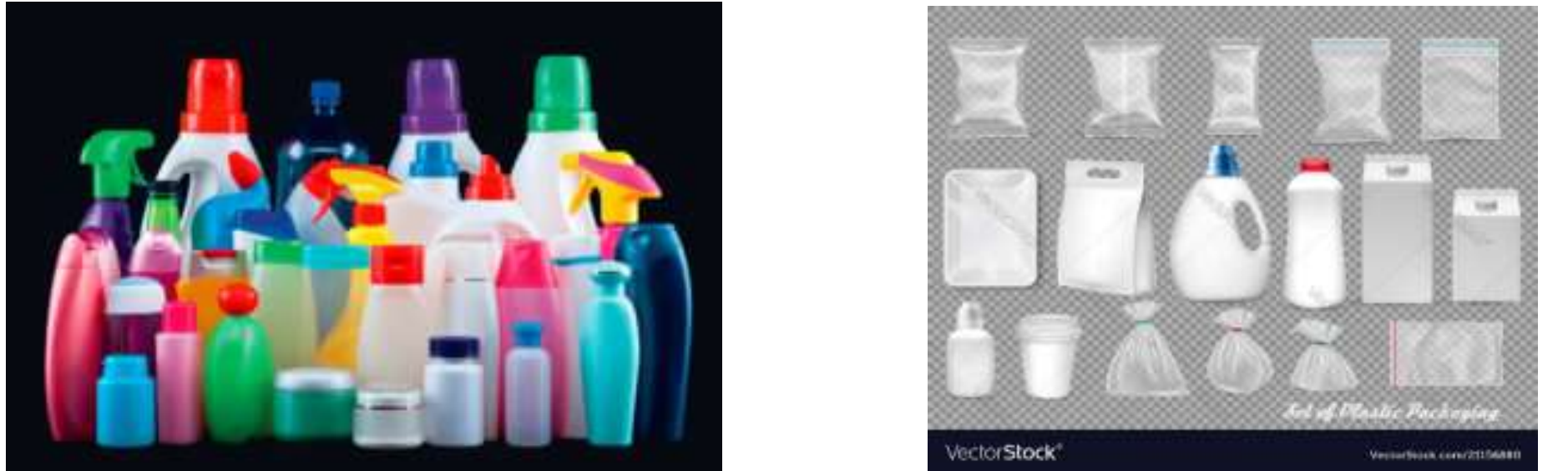

Sizes of Plastic Items in Marine Environment

The most frequent size of plastic items found in the marine environment in Qatar is between 1-5 mm. This high abundance of small size plastic particles is expected due to high residence time in the sea which further degrades the plastic, resulting in smaller fragments. Another theory is the arid climatic conditions in the region, which helps in the weathering of the plastic material, forming secondary microplastics (Dobaradaran et al., 2018).

\section{CONCLUSIONS}

It can be concluded that there is a high generation of plastic waste in the country and not enough awareness is raised within the public in order to curb the increasing rates. Additionally, the plastic waste problem in Qatar is yet to be analyzed even further, as there is a gap in literature about the recovery and recycling methods that are done in the region. The study of marine microplastics is also still at its infancy. However, there is still hope for the betterment of the environment in Qatar, as there are new initiatives being put into place for the improved handling of solid waste (plastics), and interest in sustainable ways of living is starting to rise.

\section{ACKNOWLEDGEMENTS}

This poster was supported by Qatar University Internal Grant (No. QUCG-CAS-21/22-3). The findings achieved herein are solely the responsibility of the authors

\section{REFERENCES}

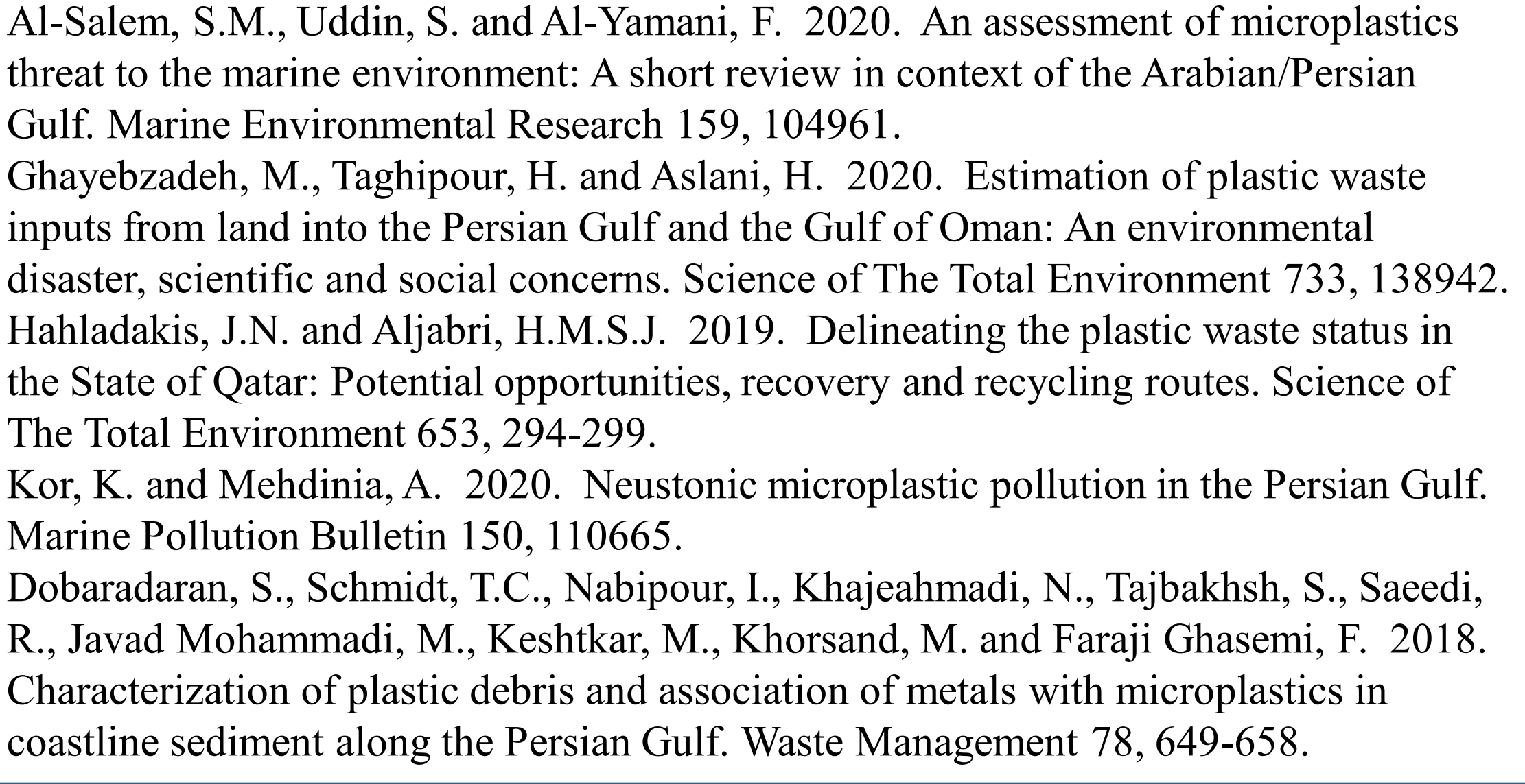

